\title{
Análise dos parâmetros fisiológicos de bezerros submetidos à mochação com auxílio do IMOBOI e implicações no bem-estar animal
}

Aline Feriato Vieira",Enrico Nogueira Tozzi,Jessica Quirino da Silva, Otávio Gasparini Marcondes, João Vitor Ribeiro Borges, Lara Jardim Coelho Koga, Barbra Martins Delgado, Guilherme Pasqual Melo, Marcelo Alves da Silva, Ana Paula Millet Evangelista dos Santos Traad

Universidade Estadual do Norte do Paraná (UENP), Bandeirantes, PR, Brasil

*Autor correspondente

e-mail: aferiatov@gmail.com

\section{Resumo}

Em rebanhos bovinos é de extrema importância a realização da descorna dos animais, pois a ausência de chifres oferece uma maior segurança para os tratadores e para os próprios animais, facilitando o manejo da propriedade. 0 procedimento da descorna pode gerar no animal intenso estresse, e devido ao bem-estar destes animais, atitudes que venham a melhorar as condições para a descorna são de grande interesse. A legislação existente somente impõe ao médico veterinário a obrigatoriedade do uso de anestesia local. Para amenizar o processo pode-se utilizar o IMOBOI ${ }^{\circledR}$. Este aparelho é um imobilizador de alta tecnologia que libera ondas eletromagnéticas de baixa intensidade, controladas por um microprocessador e transmitidas por uma sonda introduzida na região retal do animal. Este trabalho objetivou analisar possíveis alterações nos parâmetros fisiológicos de bezerros de corte, no ato da descorna zootécnica, com o auxílio do IMOBOI ${ }^{\circledR}$ para a contensão. Os parâmetros fisiológicos aferidos foram: temperatura retal (TR), Frequência Respiratória (FR), frequência cardíaca (FC) e tempo de cicatrização (TC). Além dos parâmetros fisiológicos, observou-se também o comportamento dos animais durante o ato da descorna e a duração do procedimento (DP), no intuito de identificar a utilização do dispositivo, o que traria benefício ao bem-estar dos animais mochados. Vinte bezerros da raça Nelore, em uma propriedade na região norte do Paraná, foram divididos em dois grupos: Grupo Controle (G1), onde realizou-se a descorna com imobilização dos animais somente no tronco de contensão, e Grupo IMOBOI (G2), onde a descorna foi realizada com o IMOBOI ${ }^{\circledR}$ durante todo o procedimento além do tronco de contensão. Foram aferidos os parâmetros na contenção, aplicação da anestesia, no meio do procedimento e ao final da descorna. A descorna foi realizada após 5 minutos da insensibilização no nervo cornual por infiltração de $10 \mathrm{~mL}$ de Lidocaína $2 \%$ com auxílio de termo cautério elétrico. Após a descorna aplicou-se produto repelente para se prevenir mí́ases. Não houve diferença estatística entre os grupos para nenhum dos parâmetros aferidos. Observou-se um coeficiente de variação 
alto dentro de cada grupo e para cada procedimento, e observou-se também um fator individual de comportamento bastante evidente. Os animais mostraram-se agitados durante a realização da anestesia local, o que já era esperado devido ao incômodo da agulha inserida. Notou-se que os animais com o uso do IMOBOI ${ }^{\circledR}$ apresentaram menor agitação no momento da realização da anestesia quando comparado ao grupo controle, que apresentou maior agitação e tentativa de fuga, havendo também alguns casos de vocalização durante a contenção. Conclui-se que não houve efeito do uso de IMOBOI ${ }^{\circledR}$ nos parâmetros aferidos e que mais estudos se fazem necessários para o melhor entendimento de seu mecanismo de ação e validação de resultados de campo. 